\title{
OS EFEITOS DO CAUSE-RELATED MARKETING NO COMPORTAMENTO DO CONSUMIDOR
}

\author{
THE EFFECTS OF CAUSE-RELATED MARKETING ON CONSUMER'S BEHAVIOR
}

Recebido em 18.07.2013. Aprovado em 14.05.2014 Avaliado pelo sistema double blind review

DOI: http://dx.doi.org/10.12712/rpca.v8i2.297

\author{
Renata Céli Moreira da Silva \\ renata.celi@gmail.com \\ Pontifícia Universidade Católica do Rio de Janeiro - IAG/PUC-Rio
}

Paulo Cesar de Mendonca Motta

pcmotta@iag.puc-rio.br

Pontifícia Universidade Católica do Rio de Janeiro - IAG/PUC-Rio

\section{Resumo}

A questão social vem sendo amplamente discutida. É importante que a empresa adote práticas sociais. Um programa a ser estudado é o Cause-Related Marketing - CRM. Nesse contexto, o presente estudo teve o objetivo de contribuir para um melhor entendimento dessa ferramenta, buscando investigar o comportamento dos consumidores frente aos produtos de empresas que praticam o CRM. Foi aplicado um questionário, que foi respondido por 125 consumidores. No questionário, foi apresentada uma situação hipotética de compra de pasta de dente. Os resultados mostraram que quando há marcas conhecidas pelo consumidor no mercado e uma delas tem o preço superior porque começou a realizar uma campanha de CRM, os consumidores são propensos a pagar maior preço. Entretanto, quando o cenário é de uma marca que não é conhecida, eles não estão dispostos a pagar mais caro. Vale ressaltar que os consumidores se mostraram céticos quanto à honestidade dessas campanhas de CRM.

Palavras-chave: Cause-Related Marketing, Comportamento do Consumidor, Pesquisa Quantitativa, Brasil.

\begin{abstract}
Social issues have increasingly been the focus of several discussions, hence the importance of adopting socially responsible practices in companies. In this context, Cause-Related Marketing (CRM) is a valuable tool that must be taken into account. The present study aims to contribute for a better understanding of such tool and to investigate how consumers behave towards it. One hundred and twenty five consumers were asked to answer a questionnaire that proposes a hypothetical purchase of toothpaste. The results show that if a well-known brand offers higher prices due to CRM, consumers are inclined to pay more. Nevertheless, when the brand is not well known, the opposite occurs. It is important to mention that our consumers seemed to be skeptical about how honest the CRM campaign was.
\end{abstract}

Keywords: Cause-Related Marketing, Consumer Behavior, Quantitative Research, Brazil. 


\section{Introdução}

Recentemente, a questão social vem sendo amplamente discutida, mostrando que essa é uma situação importante a ser resolvida. Pode-se dizer que o envolvimento entre as empresas e as organizações sem fins lucrativos deixou de ser voluntário de certa forma, passando a ser exigido, visto que há uma pressão da sociedade para que isso aconteça (MACHADO; DAMACENA, 2006). Essas pressões estão cada vez maiores (KLEIN, 2004; MOHR; WEBB, 2005; CHEAH; CHAN; CHIENG, 2007; HOND; BAKKER, 2007; RODRÍGUEZ; LEMASTER, 2007). Kotler e Armstrong (1998) citam que essa pressão pode ser por parte dos consumidores, que estão prestando mais atenção a essas práticas sociais.

É importante que a empresa comece a adotar práticas sociais e que mantenha a realização dessas práticas, tendo então uma continuidade, ou seja, que as práticas sociais sejam parte das atividades da empresa e não somente algo pontual. É importante que seja um processo contínuo (RANDEL, 2002; HEUGENS; DENTCHEV, 2007).

Portanto, atualmente, muitas empresas buscam investir em práticas sociais (PASSADOR; CANOPF; PASSADOR, 2005; BARBOSA, 2007). Estudos têm sido feitos considerando as ações sociais das empresas. Um programa que vem sendo estudado é o Cause-Related Marketing CRM, em que as pesquisas buscam analisar os benefícios dessa estratégia de marketing para as empresas e sociedade. Também têm sido realizados estudos para investigar as percepções dos consumidores em relação às empresas que praticam o CRM, já que, conforme dito anteriormente, tem havido uma pressão para que as empresas se preocupem mais com a sociedade.

Machado e Damacena (2006) realizaram um estudo que consistiu numa vasta revisão da literatura dos artigos que tinham por objetivo entender qual a percepção dos consumidores em relação ao CRM. Os autores sugeriram que mais estudos devem ser conduzidos, para um melhor entendimento do comportamento do consumidor e do CRM. Neste contexto, o presente artigo tem como objetivo contribuir para esse melhor entendimento, investigando como os consumidores se comportam em um ambiente em que ocorre o CRM: se eles estão dispostos a comprar o produto que defende uma causa, se eles experimentariam uma nova marca por causa da campanha, se eles pagariam mais por um produto para apoiar a causa e se eles percebem essas campanhas como sendo honestas. Dessa forma, o estudo visa contribuir para as pesquisas nacionais sobre práticas de CRM e sua influência no comportamento do consumidor.

\section{Revisão da Literatura Origem do Cause-Related Marketing (CRM)}

O CRM surgiu inicialmente nos Estados Unidos (SMITH; HIGGINS, 2000) e tem recebido atenção considerável recentemente (PRACEJUS; OLSEN, 2004). De acordo com Fisher (1980), o CRM iniciou-se nos Estados Unidos, pois é onde sempre existiu um princípio de "doing well by doing good". A origem do CRM se deu com a empresa American Express. Ela realizou uma campanha de CRM em 1981, sendo uma campanha referente a doações para programas locais de arte em São Francisco nos Estados Unidos, a partir das vendas da American Express (BARNES; FITZGIBBONS, 1991; POLONSKY; WOOD, 2001).

A American Express realizou outra campanha de CRM, episódio ocorrido em 1983 nos Estados Unidos (BARNES; FITZGIBBONS, 1991; WEBB; MOHR, 1998). A empresa lançou uma campanha de CRM em apoio à restauração da Estátua da Liberdade, que consistia na promessa de doar um centavo de dólar para cada uso feito do seu cartão e na doação de um dólar para cada novo cartão emitido nos EUA, ou seja, para cada nova afiliação durante o quarto trimestre do ano de 
1983 (VARADARAJAN; MENON, 1988).

As consequências dessa campanha foram positivas para a empresa, visto que trouxe um aumento no uso do cartão em 28\%, comparando-se ao mesmo período do ano anterior, 1982. Também causou um aumento considerável no número de novas afiliações ao cartão. Com isso, a campanha de CRM da American Express teve como resultado uma doação no valor de 1,7 milhões de dólares para fundação responsável pela restauração da Estátua da Liberdade (VARADARAJAN; MENON, 1988; BARNES; FITZGIBBONS, 1991). A American Express passou a impressão para os consumidores de que ela é responsável e patriota (BARNES; FITZGIBBONS, 1991), sendo essas características consideradas positivas, o que levou os consumidores a terem uma boa imagem da empresa.

Muitas empresas passaram a adotar também o CRM (MEYER, 1999; GRAU; FOLSE, 2007) como uma estratégia para realizar seus objetivos, como o aumento das vendas, o aumento do market share, e para estabelecer uma melhoria na imagem da empresa e do produto (ROSS; PATTERSON; STUTTS, 1992). Na década de 1980, as empresas começaram a praticar o CRM, se engajando em causas ligadas a artes e a doenças como a AIDS/HIV e o câncer. Já na década de 1990, o CRM começou a ser colocado em prática considerando também causas sociais (POLONSKY; WOOD, 2001). A partir daí, com a grande competição entre empresas, elas foram se alinhando a causas que estavam de acordo com os consumidores da empresa (MILLER, 1993). As empresas passaram a ser mais seletivas em relação a que causas escolher e apoiar, estabelecendo, dessa forma, um link entre os objetivos da empresa ou marca e a causa a ser apoiada (SMITH; HIGGINS, 2000).

No Brasil, muitas empresas praticam o CRM. Pereira e Cabral (2011) citam três organizações: Instituto Avon (campanha chamada 'Um Beijo pela Vida', que contribui para o combate ao câncer de mama), Instituto Ronald McDonald's (campanha McDia Feliz que contribui para o combate ao câncer infantil) e Fundação Arcor (campanha que consistia na doação de parte da renda da venda do chocolate 'Tortuguita Taminha' para o projeto Tamar).

\title{
Conceito de Cause-Related Marketing (CRM)
}

Recentemente, as campanhas de CRM têm crescido cada vez mais (BARNES; FITZGIBBONS, 1991; ELLEN; MOHR; WEBB, 2000; YOUN; KIM, 2008). Segundo Polonsky e Wood (2001), o CRM foi definido inicialmente por Varadarajan e Menon (1988, p. 60) como:

\begin{abstract}
"processo de formulação e implementação de atividades de marketing que são caracterizadas por um oferecimento da empresa em contribuir com uma quantia específica para uma causa designada quando os consumidores se engajam em prover trocas que propiciem resultados que satisfaçam os objetivos organizacionais e individuais".
\end{abstract}

Em outras palavras, CRM pode ser entendido como a contribuição de uma quantia de dinheiro para uma causa sem fins lucrativos, a partir da venda para consumidores (MULLEN, 1997). 0 CRM é caracterizado pelo laço que é estabelecido entre a empresa e seus produtos com uma causa (PTACEK; SALAZAR, 1997). Porter e Kramer (2002) falam que o CRM consiste na empresa concentrar suas doações em uma causa, estabelecendo uma parceria com uma organização sem fins lucrativos ou escolhendo uma causa popular.

De acordo com o "Instituto para o Desenvolvimento do Investimento Social - IDIS" - o CRM é definido como:

"uma parceria comercial entre empresas e organizações da sociedade civil que 
utiliza o poder das suas marcas em benefício mútuo... É uma ferramenta que alinha as estratégias de marketing da empresa com as necessidades da sociedade, trazendo benefícios para a causa e para os negócios".

Há um vínculo entre a doação de determinada quantia à causa e a compra de produtos ou serviços pelo consumidor. Portanto, é necessário que haja o conhecimento por parte do consumidor de que a sua participação é indispensável, caso contrário, o investimento feito pode ser desperdiçado (MACHADO; DAMACENA, 2006). Para Osterhus (1997), as empresas, ao utilizarem o CRM, estão focando em causas nas quais os consumidores se identificam e, como consequência, elas acabam incentivando esses consumidores na compra do seu produto.

Barone, Miyazaki e Taylor (2000) sugerem que o CRM é a estratégia designada para promover o alcance dos objetivos de marketing - como exemplo a venda da marca - através do suporte da empresa a causas sociais. Para Smith e Higgins (2000), o CRM é uma ferramenta de estratégia de marketing que alcança tanto os objetivos sociais quanto os empresariais.

Um dos objetivos do CRM é construir a imagem de uma marca através do reforço da reputação da empresa como uma boa cidadã. A causa deve ser consistente com a imagem que a empresa está querendo construir ou sustentar para a sua marca (TIL; NOWAK, 2000). Segundo Polonsky e Wood (2001), o CRM pode trazer benefícios para as empresas, para as instituições sem fins lucrativos e para os consumidores, sendo, portanto, uma situação ganha-ganha entre as partes (SMITH; HIGGINS, 2000).

Há diversos benefícios que uma empresa pode obter a partir do CRM. Na Tabela 1, é apresentada uma síntese dos principais benefícios ligados à prática do CRM nas empresas.

\begin{tabular}{|l|l|}
\hline \multicolumn{1}{|c|}{ Benefícios do CRM } & \multicolumn{1}{|c|}{ Autores } \\
\hline Aumento das vendas & $\begin{array}{l}\text { Ross et al. (1992); Smith (1994); Andreasen (1996); } \\
\text { Smith e Higgins (2000); Polonsky e Wood (2001); } \\
\text { Bronn e Vrioni (2001); Larson et al. (2008) }\end{array}$ \\
\hline Aumento do market share & $\begin{array}{l}\text { Varadarajan e Menon (1988); Smith e Alcorn (1991); } \\
\text { Ross et al. (1992) }\end{array}$ \\
\hline Melhoria na imagem da empresa & $\begin{array}{l}\text { Varadarajan e Menon (1988); Barnes e Fitzgibbons } \\
\text { (1991); Ross et al. (1992); Drumwright (1994); File e } \\
\text { Prince (1998); Ellen et al. (2000); Smith e Higgins } \\
\text { (2000); Til e Nowak (2000); Bronn e Vrioni (2001); } \\
\text { Mohr et al. (2001); Polonsky e Wood (2001); Porter } \\
\text { Kramer (2002) }\end{array}$ \\
\hline Melhoria na imagem do produto & Ross et al. (1992); Polonsky e Wood (2001) \\
\hline $\begin{array}{l}\text { Possui maior impacto do que uma } \\
\text { filantropia sem foco }\end{array}$ & Porter e Kramer (2002) \\
\hline $\begin{array}{l}\text { Possibilita medição do retorno } \\
\text { financeiro }\end{array}$ & Smith e Alcorn (1991) \\
\hline $\begin{array}{l}\text { Minimiza os efeitos causados por } \\
\text { uma publicidade negativa }\end{array}$ & Varadarajan e Menon (1988); Polonsky e Wood (2001) \\
\hline Ajuda as causas & $\begin{array}{l}\text { Ross et al. (1992); Ptacek e Salazar (1997); Webb e } \\
\text { Mohr (1998) }\end{array}$ \\
\hline $\begin{array}{l}\text { Motiva os funcionários, eleva a } \\
\text { moral dos funcionários }\end{array}$ & $\begin{array}{l}\text { Mullen (1997); Bronn e Vrioni (2001); Polonsky e } \\
\text { Wood (2001) }\end{array}$ \\
\hline Maior visibilidade no mercado & Varadarajan e Menon (1988); Porter e Kramer (2002) \\
\hline Diferenciação & Shell (1989); Ellen et al. (2000) \\
\hline $\begin{array}{l}\text { Melhoria no relacionamento com } \\
\text { o consumidor }\end{array}$ & Ellen et al. (2000) \\
\hline
\end{tabular}

Tabela 1: Síntese dos benefícios do CRM

Fonte: Elaborado com base na revisão da literatura 
A definição de CRM pode ser confundida em algumas situações. Um exemplo de empresa que pratica o CRM é o McDonald's na campanha "McDia Feliz". Essa campanha consiste no repasse do dinheiro referente à compra do Big Mac, em um determinado dia, para instituição de combate ao câncer infanto-juvenil. Portanto, num determinado dia anunciado pelo McDonald's, todo o dinheiro referente às compras do Big Mac é repassado para certa instituição (MCDONALD'S, 2009).

Outro exemplo de CRM foi o programa promovido pela Coca-Cola Brasil, chamado "Semana Otimismo que transforma", que consistiu no seguinte: durante um determinado período, cada embalagem vendida de qualquer produto do portfólio da Coca-Cola Brasil, como refrigerantes, sucos, águas, chás, energéticos e hidrotônicos, reverteu dois centavos e meio para os programas desenvolvidos pelo Instituto Coca-Cola Brasil (COCA-COLA, 2009).

O CRM vem crescendo bastante e muitas empresas vêm adotando essas campanhas. Só nos EUA, na década passada, as empresas destinaram a causas sociais um valor superior a 1 bilhão de dólares (BARONE et al., 2000). Webb e Mohr (1998) também relatam que, de 1990 a 1993, houve um aumento de mais de 150\% nas despesas com CRM das empresas localizadas nos EUA. Adicionalmente, um estudo mostrou que os investimentos norte-americanos em CRM cresceram de 125 milhões de dólares em 1990 para 828 milhões de dólares em 2002 (PORTER; KRAMER, 2002).

Contudo, Bronn e Vrioni (2001) alertam que o CRM pode ser muito perigoso para a empresa, caso ela não saiba agir da forma correta. Varadarajan e Menon (1988) falam que as empresas que colocam em prática o CRM podem estar vulneráveis a críticas feitas ao seu potencial de abuso das causas. Um exemplo de risco que o CRM pode estabelecer para uma organização sem fins lucrativos é que ela pode perder a credibilidade, caso ela se associe a uma empresa com uma imagem ruim perante a sociedade (KOTLER; ANDREASEN, 1996). 0 mesmo pode ser dito, caso uma empresa se associe a uma instituição que não é "séria".

Por isso, é interessante que se estude a percepção dos consumidores sobre o CRM, para que se possa saber o que os consumidores pensam sobre essas práticas que muitas empresas estão adotando.

\section{Críticas ao Cause-Related Marketing}

Apesar de haver benefícios na prática do CRM pelas empresas, também existem críticas. Varadarajan e Menon (1988), que definiram o termo inicialmente, apontaram as possíveis críticas que poderiam ser feitas ao CRM, dependendo de como ele fosse utilizado. As principais críticas resumidas que foram abordadas no artigo dos autores são:

- As empresas podem se engajar nessas campanhas somente para obter ganhos, sendo puramente uma estratégia de marketing, sem se preocupar de fato com quem está sendo ajudado.

- O dinheiro gasto pelas empresas nas ações de promoção das campanhas de CRM pode ser muito mais alto que o dinheiro doado na campanha, o que torna a prática do CRM pela empresa um alvo fácil para as críticas.

- As empresas podem se engajar em campanhas como essas para obter subsídios do governo.

- As empresas podem ser vistas como empresas exploradoras. 
Nesse contexto, o CRM pode ser visto pelos consumidores como uma prática duvidosa, despertando o ceticismo do consumidor (WEBB; MOHR, 1998), que precisa de provas quanto à honestidade da empresa.

Polonsky e Wood (2001) também citam críticas ao CRM, apontando consequências que podem ser ruins para a sociedade. Segundo os autores, a prática de CRM pelas empresas pode 'cegar' o consumidor, fazendo com que ele veja de uma forma exageradamente positiva a preocupação da empresa com a sociedade. Além disso, uma empresa pode escolher uma causa que tem mais atratividade em termos promocionais e de marketing, sem se preocupar se esta realmente é a melhor causa, a que terá um impacto mais positivo na sociedade; e a empresa pode também reduzir suas doações em geral, já que está praticando o CRM, o que contribui para a desconfiança do consumidor (POLONSKY; WOOD, 2001).

Meyer (1999) adiciona uma crítica ao CRM, que diz respeito à possibilidade de que as empresas aumentem o preço do produto a ser vendido na campanha para a manutenção de seus lucros.

\section{Estudos Anteriores sobre Cause-Related Marketing na Ótica do Consumidor}

Pesquisadores investigaram os efeitos do CRM no comportamento do consumidor. Alguns autores mostraram evidências de que os consumidores que são preocupados em passar uma boa imagem de si próprios são mais propensos a comprar produtos que contribuem para programas de CRM (YOUN; KIM, 2008).

Strahilevitz e Myers (1998) fizeram um estudo que obteve evidências de que o CRM obtém mais respostas positivas dos consumidores quando ele é relacionado a produtos de luxo do que produtos de primeira necessidade. 0 estudo fez um experimento onde o produto de luxo era um sundae e o produto de primeira necessidade era o detergente. É possível que os sentimentos de culpa que podem ser gerados nos consumidores ao fazer compras de bens de luxo acabam sendo dissolvidos se a compra estiver ligada a uma causa.

Estudos também mostraram que o CRM influencia a decisão de compra do consumidor, quando considerado um ambiente de marcas contendo o mesmo preço e desempenho/qualidade (BARONE et al., 2000; BRONN; VRIONI, 2001). Por outro lado, Boulstridge e Carrigan (2000) tiveram evidências em suas pesquisas de que o consumidor não considerava o comportamento das empresas importante para influenciar sua decisão de compra.

Pesquisas também trouxeram evidências de que os consumidores, muitas vezes, são céticos quanto aos programas de CRM, gerando então, atitudes negativas nesses indivíduos (WEBB; MOHR, 1998). Outras compararam homens e mulheres no que tange às atitudes em relação aos apelos sociais dos produtos, trazendo evidências de que as mulheres estão mais sujeitas a terem atitudes positivas (ROSS et al., 1992; BERGER; CUNNINGHAM; KOZINETS, 1999). Os homens costumam ter mais percepções de que as empresas estão explorando as causas. Pesquisas também apontaram as mulheres como sendo mais prováveis a experimentarem novas marcas que estão ligadas ao CRM (ROSS et al., 1992).

Ellen et al. (2000) realizaram um estudo em que uma das variáveis que tentaram medir foi a questão do tipo da causa - se era um desastre, ou uma causa em curso, como exemplo meio ambiente, pobreza, doença. Os resultados mostraram que os consumidores se mobilizavam mais com as causas ligadas a desastres - como terremoto.

Pesquisa recente de Farache, Perks, Wanderley et al. (2008) apontou que os consumidores percebem de forma positiva quando uma empresa faz parceria com uma organização sem fins lucrativos, apesar de terem consciência de que a empresa pode usufruir de benefícios dessa 
parceria.

No Brasil, Novais, Sousa, Melo et al. (2010) realizaram uma pesquisa para investigar se o CRM era capaz de influenciar o comportamento de compra de produtos. A pesquisa foi feita na cidade de Belo Horizonte. $O$ estudo obteve evidências de que o CRM influencia a compra de produtos de forma positiva, principalmente se forem causas relacionadas à saúde ou ao combate à fome.

\section{Metodologia}

A presente pesquisa é caracterizada como uma pesquisa descritiva. A metodologia usada foi de natureza quantitativa. A pesquisa foi realizada da seguinte forma: baseando-se em alguns dos estudos feitos internacionalmente mostrados na revisão da literatura, buscou-se investigar a influência dos fatores 'preço' e 'marca nova' na compra de produtos que participam de campanhas de CRM. Buscou-se também pesquisar sobre a percepção dos consumidores em relação à honestidade dessas campanhas.

Para instrumentalizar esse objetivo, foi elaborado um questionário contendo diferentes situações, em que os consumidores teriam que se imaginar nessas situações e dizer como reagiriam. 0 produto escolhido para ser o foco da pesquisa foi a pasta de dente, pois é um produto que a maioria das pessoas utiliza, possui um custo relativamente baixo e também realiza publicidade na mídia. A campanha de CRM descrita no questionário buscava ajudar uma instituição na alfabetização de crianças carentes. As situações do questionário eram as seguintes:

- Situação 1: Havia duas marcas que o consumidor estava acostumado a consumir e ambas custavam o mesmo preço. Porém, uma delas se engaja numa campanha de CRM e o seu preço aumenta em vinte centavos e, então, o consumidor tem que decidir se ele compraria essa marca que realiza a campanha.

- Situação 2: Havia duas marcas que o consumidor estava acostumado a consumir e ambas custavam o mesmo preço. Contudo, ocorre o lançamento de uma nova marca, que o consumidor ainda não conhece, porém que está realizando uma campanha de CRM, mas que o seu preço é o mesmo das outras duas marcas. Nesse cenário, o consumidor tem que decidir se compraria esse produto.

- Situação 3: Havia duas marcas que o consumidor estava acostumado a consumir e ambas custavam o mesmo preço. Entretanto, outra marca começa a fazer uma campanha de CRM e o seu preço é maior em $\mathrm{R} \$ 0,20$, por causa da campanha. Nesse caso, o consumidor também precisa decidir se compraria o produto.

Nas três situações, as questões eram respondidas através de uma escala Likert de 5 pontos, sendo 1 para "Discordo Totalmente" até 5 para "Concordo Totalmente". Além dessas situações, os entrevistados responderam questões sobre o seu nível de ceticismo em relação a essas campanhas de CRM e essas questões eram respondidas numa escala de 1 a 10, sendo 1 para “Pouco Provável” e 10 para "Muito Provável”.

A coleta de dados foi feita da seguinte forma: o questionário foi enviado pela internet para diversas pessoas e essas, por sua vez, enviavam para outras pessoas da sua lista de contatos. As pessoas iam respondendo os e-mails e encaminhando os questionários respondidos. 0 total de indivíduos que respondeu foi 125. Dentre eles, 68 eram do sexo feminino (54\%) e 57 do sexo masculino (46\%). Em relação ao nível de escolaridade, 30 pessoas (24\%) tinham até o $2^{\circ}$ grau completo (muitos com nível superior em andamento), 49 tinham o nível superior completo (39\%) e 46 pessoas tinham pós-graduação completa (37\%). No que diz respeito à idade, 41 
respondentes tinham até 25 anos (26\%), 51 tinham entre 26 e 40 anos (41\%) e 33 pessoas tinham a partir de 41 anos (26\%).

O tratamento dos dados foi feito através de análise estatística utilizando o SPSS 15.0. Foi realizado o teste t para as questões com escala Likert de 5 pontos (onde a hipótese nula era Ho: $\mu=3$, sendo 3 igual a escala "Nem Discordo, Nem Concordo"), e foi feito o teste para comparar duas médias, para dessa forma, realizar uma comparação entre os gêneros feminino e masculino.

Porém, o presente método apresenta limitações. Uma das limitações consistiu no fato de que os consumidores foram confrontados com situações hipotéticas e não participaram de uma experiência real. Tentou-se superar essa limitação, descrevendo as situações hipotéticas de forma bastante explicada, para que não houvesse dúvidas e que o consumidor pudesse se imaginar na situação da forma mais real possível. Outra limitação é o fato de o público pesquisado ter sido escolhido por conveniência, não tendo sido utilizada a amostragem probabilística.

\section{Análise dos Resultados Situação 1:}

Conforme descrito anteriormente, a situação 1 consiste na existência de duas marcas que o consumidor estava acostumado a consumir, Alfa e Beta, e ambas custavam o mesmo preço, R\$ 2,00. Porém, uma delas, a marca Alfa, se engaja numa campanha de CRM para ajudar uma instituição na alfabetização de crianças carentes, e o seu preço aumenta para $R \$ 2,20$ e, então, o consumidor tem que decidir qual marca ele compraria. Diante deste cenário, os entrevistados tinham que responder três questões: (1) Se hoje eu for comprar pasta de dente, eu compraria Alfa; (2) Durante a campanha para doação, eu só compraria Alfa; (3) Durante a campanha para doação, eu não compraria Beta. As respostas foram dadas em uma escala Likert de 5 pontos. Na Tabela 2, são apresentados os resultados da média e da estatística t.

\begin{tabular}{|l|c|c|c|c|}
\hline Questões & Média & Des vio Padrão & $\begin{array}{l}\text { Nível de significância } \\
\text { (teste t - 2 tailed })\end{array}$ & Significante? \\
\hline $\begin{array}{l}\text { 1- Se hoje eu for comprar pasta de dente, eu } \\
\text { compraria Alfa }\end{array}$ & 3,73 & 1,358 & 0,000 & Sim \\
\hline $\begin{array}{l}\text { 2- Durante a campanha para doação, eu só } \\
\text { compraria Alfa }\end{array}$ & 3,42 & 1,427 & 0,000 & Sim \\
\hline $\begin{array}{l}\text { 3- Durante a campanha para doação, eu não } \\
\text { compraria Beta }\end{array}$ & 2,94 & 1,444 & 0,665 & Não \\
\hline
\end{tabular}

Tabela 2: Estatística - Situação 1

Analisando a Tabela 2, pode ser visto pelas médias que na questão 1 a resposta é próxima a "Concordo em parte", ou seja, se hoje os consumidores fossem comprar pasta de dente, eles comprariam a marca que realiza a campanha de CRM, mesmo que o seu preço esteja maior por causa dessa iniciativa. Pelo nível de significância do teste t, há evidências de que os indivíduos comprariam hoje a pasta de dente Alfa, que realiza a campanha de CRM e com isso, possui um preço superior. Apesar de autores relatarem que o consumidor dá importância às empresas que praticam o CRM quando o preço não é superior (BARONE et al., 2000; BRONN; VRIONI, 2011), os respondentes se mostraram propensos a consumir mesmo quando o preço é maior (em um cenário de marcas conhecidas). Isso pode acontecer devido ao conhecimento da qualidade e desempenho dos produtos - também relatado por Barone et al. (2000) e Bronn e Vrioni (2011) - e pelo fato de os consumidores quererem ajudar a causa, unindo "o útil ao agradável” (ROSS et 
al., 1992; PTACEK; SALAZAR, 1997; WEBB; MOHR, 1998).

Em relação à questão 2, a estatística t também foi significante a um nível de $1 \%$. Analisando a média, também pode ser visto que foi superior a 3. Com isso, há evidências de que durante a campanha de CRM, os indivíduos só comprariam Alfa. A questão 3 não obteve um teste $\mathrm{t}$ significante, conforme pode ser visto na Tabela 3. Logo, não há evidências suficientes de que durante a campanha para doação, as pessoas não comprariam Beta.

Portanto, pode ser visto que em um cenário de duas marcas conhecidas com o mesmo preço, em que o consumidor está acostumado a comprar as duas, caso uma delas passe a realizar uma campanha de CRM e que para isso ela tenha que aumentar o seu preço, mesmo assim, os consumidores estariam dispostos a comprar essa marca. Isso mostra a propensão a comprar um produto que realiza uma campanha de CRM, o que vai contra a pesquisa realizada por Boulstridge e Carrigan (2000). Vale ressaltar que, neste caso, é uma marca conhecida pelo consumidor.

Também foi realizado um teste para saber se há diferenças entre as médias de homens e mulheres. Em relação à questão 1 ("Se hoje eu for comprar pasta de dente, eu compraria Alfa"), o teste foi significante e a média do sexo feminino foi 4,07 e do sexo masculino foi 3,32 , mostrando evidências de que as mulheres estariam, hoje, mais propensas a comprar a marca que pratica o CRM, mesmo com um preço mais alto.

Em relação à questão 2 ("Durante a campanha para doação, eu só compraria Alfa"), o teste foi significante a $10 \%$ e a média do sexo feminino foi 3,63 e a do sexo masculino foi 3,16, indicando também evidências de que as mulheres possuem maior propensão a comprar a marca que pratica o CRM, conforme mostram pesquisas de Ross et al. (1992) e Berger et al. (1999). Já a questão 3 ("Durante a campanha para doação, eu não compraria Beta") não teve seu teste estatístico significante.

\section{Situação 2}

Conforme descrito anteriormente, a situação 2 consiste na existência de duas marcas que o consumidor estava acostumado a consumir, Alfa e Beta, e ambas custavam o mesmo preço, $\mathrm{R} \$$ 2,00. Contudo, ocorre o lançamento de uma nova marca de pasta de dente que o consumidor ainda não conhece, a marca Gama, sendo que a marca Gama está fazendo uma campanha de CRM. Ela custa o mesmo preço, $\mathrm{R} \$ 2,00$, sendo que este preço inclui o valor de $\mathrm{R} \$ 0,20$ para a doação. Diante deste cenário, os entrevistados tinham que responder três questões: (4) Se hoje eu for comprar pasta de dente, eu compraria Gama; (5) Durante a campanha para doação, eu só compraria Gama; (6) Durante a campanha para doação, eu não compraria nem Alfa nem Beta. As respostas foram dadas em uma escala Likert de 5 pontos. Na Tabela 3, são mostrados os resultados da média e da estatística t.

\begin{tabular}{|l|c|c|c|c|}
\hline Questões & Média & Desvio Padrão & $\begin{array}{l}\text { Nível de significância } \\
\text { (teste t - 2 tailed })\end{array}$ & Significante? \\
\hline $\begin{array}{l}\text { 4- Se hoje eu for comprar pasta de dente, eu } \\
\text { compraria Gama }\end{array}$ & 3,82 & 1,310 & 0,000 & Sim \\
\hline $\begin{array}{l}\text { 5- Durante a campanha para doação, eu só } \\
\text { compraria Gama }\end{array}$ & 2,94 & 1,366 & 0,601 & Não \\
\hline $\begin{array}{l}\text { 6- Durante a campanha para doação, eu não } \\
\text { compraria nem Alfa nem Beta }\end{array}$ & 2,46 & 1,371 & 0,000 & Sim \\
\hline
\end{tabular}

Tabela 3: Estatística - Situação 2 
Em relação à questão 4, a estatística $t$ foi significante, mostrando que há evidências de que se os consumidores comprassem pasta de dente hoje, eles comprariam Gama. Apesar de os respondentes não conhecerem a marca Gama, que está entrando no mercado, eles se dizem dispostos a comprá-la devido à campanha de CRM. Esse resultado corrobora com estudos que dizem que o CRM atrai consumidores dispostos a ajudar causas sociais (ROSS et al., 1992; WEBB; MOHR, 2011). Como os consumidores respondentes relataram que poderiam experimentar essa nova marca devido ao CRM, utilizar essa estratégia de marketing pode ser uma diferenciação para a empresa (SHELL, 1989; ELLEN et al. 2000) e, como consequência, proporcionar uma imagem positiva da marca (VARADARAJAN; MENON, 1988; SMITH; HIGGINS, 2000; TIL; NOWAK, 2000; BRONN; VRIONI, 2001; PORTER; KRAMER, 2002).

No que diz respeito à questão 5 , a estatística $t$ não foi significante, não havendo, então, evidências de que os consumidores só comprariam Gama durante a campanha de CRM. A questão 6 teve o teste t significante a 1\% e sua média foi 2,46. Nesse caso, há evidências de que os consumidores discordam de que não comprariam nem Alfa nem Beta durante a campanha de CRM, ou seja, eles poderiam comprar essas marcas, mesmo tendo outra marca no mercado, a marca Gama, realizando a campanha de CRM.

Neste caso, pode-se dizer que os consumidores poderiam comprar a marca Gama, mas não se prenderiam somente a essa marca. Eles poderiam comprar a marca Gama hoje, mas durante toda a campanha de CRM, isso não os impediria de comprar Alfa e Beta também. Ou seja, pode ser visto que em um caso de lançamento de uma nova marca, os consumidores podem até comprar essa marca que pratica a campanha de CRM, mas isso não fará com que os consumidores só comprem dessa nova marca durante o programa de CRM. Vale ressaltar que esse é um cenário de preços iguais, ou seja, não houve aumento de preço para realizar a campanha de CRM. Isso está de acordo com pesquisas de Barone et al. (2000) e Bronn e Vrioni (2001) que indicaram que em um cenário com preços iguais os consumidores mostram que há possibilidades de comprar da empresa que realiza a campanha.

Também foi realizado um teste para saber se há diferenças entre as médias de homens e mulheres. Em relação à questão 4 ("Se hoje eu for comprar pasta de dente, eu compraria Gama"), o teste foi significante a 1\% e a média do sexo feminino foi 4,12 e do sexo masculino foi 3,46. Assim, o teste mostra evidências de que as mulheres estariam hoje mais propensas a comprar a marca que pratica o CRM, mesmo sendo uma marca nova, apesar de ter o mesmo preço das outras marcas que costumam comprar. Essa maior propensão das mulheres a experimentar uma nova marca está de acordo com a pesquisa de Ross et al. (1992). Os resultados também corroboram com estudos de Berger et al. (1999) que dizem que as mulheres são mais dispostas a ter atitudes positivas em relação a produtos de empresas que praticam o CRM.

Em relação à questão 5 ("Durante a campanha para doação, eu só compraria Gama"), o teste foi significante a $5 \%$ e a média do sexo feminino foi 3,19 e a do sexo masculino foi 2,63. Portanto, há evidências de que os homens possuem uma menor propensão a comprar somente a marca que pratica o CRM. A questão 6 ("Durante a campanha para doação, eu não compraria nem Alfa nem Beta") também teve seu teste estatístico significante a 5\% e a média feminina foi 2,71 e a média masculina foi 2,18, mostrando evidências de que os homens são mais propensos a comprar as marcas Alfa e Beta, que não realizam o CRM, mesmo sabendo que há outra marca que está desenvolvendo uma campanha. Esse resultado pode estar relacionado ao que Ross et al. (1992) relataram sobre os homens acharem que essas campanhas buscam explorar a causa, sem ter o objetivo de ajudar realmente. 


\section{Situação 3}

Conforme descrito anteriormente, a situação 3 consiste na existência de duas marcas de pasta de dente que o consumidor gosta de comprar, a marca Alfa e a marca Beta e essas duas marcas custam o mesmo preço: $\mathrm{R} \$ 2,00$. Outra pasta de dente chamada Ômega começa a fazer uma campanha de CRM e o preço de Ômega é $\mathrm{R} \$ 2,20$, sendo que este preço inclui o valor de $\mathrm{R} \$ 0,20$ para a doação. Diante deste cenário, os entrevistados tinham que responder três questões: (7) Se hoje eu for comprar pasta de dente, eu compraria Ômega; (8) Durante a campanha para doação, eu só compraria Ômega; (9) Durante a campanha para doação, eu não compraria nem Alfa nem Beta. As respostas foram dadas em uma escala Likert de 5 pontos. A Tabela 4 mostra os resultados da média e da estatística t.

\begin{tabular}{|l|c|c|c|c|}
\hline Questões & Média & Des vio Padrão & $\begin{array}{l}\text { Nível de significância } \\
\text { (teste t - 2 tailed })\end{array}$ & Significante? \\
\hline $\begin{array}{l}\text { 7- Se hoje eu for comprar pasta de dente, eu } \\
\text { compraria Ômega }\end{array}$ & 3,00 & 1,391 & 1,000 & Não \\
\hline $\begin{array}{l}\text { 8- Durante a campanha para doação, eu só } \\
\text { compraria Ômega }\end{array}$ & 2,30 & 1,239 & 0,000 & Sim \\
\hline $\begin{array}{l}\text { 9- Durante a campanha para doação, eu não } \\
\text { compraria nem Alfa nem Beta }\end{array}$ & 2,11 & 1,165 & 0,000 & Sim \\
\hline
\end{tabular}

Tabela 4: Estatística - Situação 3

Analisando os resultados estatísticos da questão 7, pode ser visto que a estatística t não foi significante, sendo a média exatamente igual a 3. Ou seja, nesse caso, pode ser visto que não há evidências de que se os consumidores fossem fazer a compra hoje, eles comprariam Ômega. Em relação à questão 8, a estatística t foi significante. Nesse caso, há evidências de que os consumidores não comprariam somente a marca Ômega durante a campanha de CRM, isto é, eles poderiam comprar Alfa e Beta também. A questão 9 também teve seu teste $t$ significante, havendo evidências de que os consumidores discordam de que não comprariam nem Alfa nem Beta durante a campanha de CRM, indicando que eles poderiam comprar essas marcas, mesmo tendo outra marca no mercado, a marca Ômega, realizando a campanha de CRM.

Portanto, os resultados da situação 3 mostram evidências de que os consumidores não deixariam de comprar as marcas que estão acostumados a consumir para comprar outra marca que esteja realizando uma campanha de CRM com um preço superior ao das marcas que eles costumam comprar. Por conseguinte, pode ser vista uma sensibilidade ao preço neste cenário, como mostra o artigo de Bronn e Vrioni (2001). Como os respondentes não conhecem a marca Ômega e, assim, não sabem seu nível de qualidade e desempenho, além de ter um preço superior, não são atraídos por esse produto que ajuda uma causa. Autores citam a importância dos atributos preço e desempenho/qualidade de um produto para a decisão de compra do consumidor (BARONE et al., 2000; BRONN; VRIONI, 2001). Logo, num cenário onde esses atributos mudam ou são mais difíceis de serem percebidos, o consumidor parece não ter disposição a se arriscar, mesmo para ajudar uma causa social.

Em relação à comparação entre os gêneros feminino e masculino, quanto à questão 7 ("Se hoje eu for comprar pasta de dente, eu compraria Ômega"), o teste foi significante a 1\% e a média do sexo feminino foi 3,32 e do sexo masculino foi 2,61. Dessa forma, houve evidências de que os homens estariam hoje mais propensos a não comprar a marca que pratica o CRM, que é uma marca que não é frequentemente utilizada e que está com preço maior, por causa da campanha.

Em relação à questão 8 ("Durante a campanha para doação, eu só compraria Ômega”), o teste foi 
significante a $1 \%$ e a média do sexo feminino foi 2,62 e a do sexo masculino foi 1,93 , indicando evidências de que os homens possuem uma menor propensão a comprar somente a marca que pratica o CRM, apesar do fato de que as mulheres também não estão dispostas a comprar somente essa marca.

A questão 9 ("Durante a campanha para doação, eu não compraria nem Alfa nem Beta") teve seu teste estatístico significante a $5 \%$ e a média feminina foi 2,31 e a média masculina foi 1,88 , mostrando evidências de que os homens são mais propensos a comprar as marcas Alfa e Beta, que não realizam o CRM, mesmo sabendo que há outra marca que está desenvolvendo uma campanha, apesar do fato de que as mulheres também indicam que estão propensas a essa compra de Alfa e Beta. Portanto, no presente cenário, os resultados também corroboram com estudos anteriores que apontam que os homens são menos propensos que as mulheres a apoiarem uma causa social por meio da compra de um produto (ROSS et al., 1992; BERGER et al., 1999).

\section{Nível de Ceticismo dos Consumidores}

Para analisar o nível de ceticismo dos consumidores foram elaboradas quatro questões: (10) Qual a probabilidade das campanhas serem honestas na doação que será feita; (11) Qual a probabilidade de que seja doado todo o valor acrescentado no preço do produto vendido; (12) Qual a probabilidade de que o interesse nessa campanha seja somente aumentar as vendas; (13) Qual a probabilidade de que o interesse nessa campanha seja realmente ajudar a instituição. Essas questões foram respondidas numa escala de 1 (pouco provável) até 10 (muito provável). Na Tabela 5, são apresentadas as médias das questões.

\begin{tabular}{|l|c|}
\hline \multicolumn{1}{|c|}{ Questões } & Médias \\
\hline $\begin{array}{l}\text { 10- Qual a probabilidade de essas campanhas serem } \\
\text { honestas na doação que será feita? }\end{array}$ & 6,31 \\
\hline $\begin{array}{l}\text { 11- Qual a probabilidade de que seja doado todo o valor } \\
\text { que foi acrescentado no preço do produto vendido? }\end{array}$ & 5,58 \\
\hline $\begin{array}{l}\text { 12. Qual a probabilidade de que o interesse com essa } \\
\text { campanha seja somente aumentar as vendas? }\end{array}$ & 8,00 \\
\hline $\begin{array}{l}\text { 13. Qual a probabilidade de que o interesse com essa } \\
\text { campanha seja realmente ajudar a instituição? }\end{array}$ & 4,38 \\
\hline
\end{tabular}

Tabela 5: Média das Questões 10-13

Observando as médias, pode-se ver que a questão 12 teve uma nota muito alta, igual a 8, mostrando que os consumidores pesquisados acreditam que existe uma grande probabilidade de que o interesse da empresa com a campanha de CRM seja somente o de aumentar as vendas. Outra nota que se destacou, porém como nota baixa, foi a da questão 13 , sendo igual a 4,38, indicando que os indivíduos pesquisados acham que há uma baixa probabilidade de que o interesse da empresa com a campanha de CRM seja realmente ajudar a causa.

Já em relação às questões 10 e 11, que dizem respeito ao nível de ceticismo dos consumidores, as suas médias ficaram no meio da escala, mostrando que eles não possuem uma grande confiança na honestidade das campanhas de CRM, como mostra também a pesquisa de Webb e Mohr (1998), corroborando com as críticas feitas ao CRM.

Como foi visto anteriormente, a prática do CRM é alvo de muitas críticas como a preocupação somente em aumentar vendas e não com a sociedade, ou até gastar mais dinheiro com 
publicidade do CRM do que com a doação, sendo uma visão exploradora da causa (VARADARAJAN; MENON, 1988), que dá margens à desconfiança do consumidor (WEBB; MOHR, 1998; POLONSKY; WOOD, 2011).

Bronn e Vrioni (2001) alertaram sobre a visão crítica dos consumidores, que podem perceber as empresas que praticam o CRM como exploradoras de determinada causa. Os autores sugerem que as empresas utilizem essa estratégia de marketing de forma cautelosa e transparente, para evitar ceticismo e críticas dos consumidores.

Também foi realizado o teste para verificar se há diferença entre as médias do sexo feminino e do sexo masculino em relação às questões que medem o nível de ceticismo dos consumidores (questões 10 a 13). Entretanto, nenhum dos testes foi significante, tendo as médias das mulheres e dos homens muito próximas.

\section{Considerações Finais}

Como foi visto, existem estudos feitos por pesquisadores internacionais sobre a influência da prática de CRM no comportamento do consumidor. A presente pesquisa buscou investigar essa influência no cenário brasileiro. Para isso, baseando-se em estudos anteriores, foram estabelecidos os seguintes tópicos a serem estudados: propensão a comprar um produto de uma empresa que pratica o CRM em caso de preço superior; propensão a comprar um produto novo no mercado, que não é conhecido ainda, mas que está ligado a uma campanha de CRM; propensão a comprar um produto de uma marca que o consumidor não costuma comprar, porém que está ligado a uma campanha de CRM e que tem um preço superior; nível de ceticismo dos consumidores em relação a essas campanhas; comparação entre homens e mulheres em relação aos tópicos anteriores.

Os resultados mostraram que, quando um consumidor possui duas marcas nas quais ele costuma comprar e uma delas passa a ter uma campanha de CRM e por causa disso aumenta o seu preço, os consumidores, de forma geral, se veem propensos a comprar desta marca. Além disso, as mulheres são mais propensas do que os homens a realizarem essas compras.

Em relação ao cenário em que uma nova marca entra no mercado, porém com uma campanha de CRM a um preço igual ao das marcas que os consumidores estão acostumados a comprar, também houve evidências de que existe uma propensão por parte dos consumidores, de forma geral, a comprarem essa nova marca. Nesse caso, as mulheres também se mostraram mais propensas a comprar a marca ligada ao CRM, mesmo sendo uma marca nova, isto é, as mulheres são mais propensas a experimentar uma nova marca do que os homens, neste cenário.

No que diz respeito à compra de outra marca que não é a de costume dos consumidores, que está realizando uma campanha de CRM e por causa disso tem seu preço superior, o resultado mostrou que existe uma sensibilidade ao preço por parte dos consumidores, indicando que eles não são propensos a comprá-la.

Nesse contexto, o estudo obteve evidências de que quando o cenário é de marcas conhecidas, mas uma tem o preço superior porque começa a realizar uma campanha de CRM, os consumidores são propensos a pagar um preço maior. Entretanto, quando o cenário é de uma marca que não é conhecida, a percepção deles muda e eles não estão dispostos a pagar mais caro.

Outro resultado interessante foi o nível de ceticismo em relação às campanhas. Os consumidores em geral, tantos os homens quanto as mulheres, se mostraram céticos quanto à honestidade dessas campanhas. Soma-se a isso o fato de os consumidores acharem que há grande 
probabilidade de que o interesse das empresas nessas campanhas seja somente o de aumentar as vendas e que existe pouca probabilidade de que essas campanhas sejam feitas realmente para ajudar as instituições.

Esse resultado é interessante para as empresas, pois mostra que elas precisam agir de forma que transmitam mais confiança para os consumidores. As empresas poderiam ser mais transparentes em relação às suas ações quando realizam esse tipo de campanha, para que os consumidores possam ter conhecimento de que realmente essa campanha está sendo efetivada. As empresas poderiam divulgar o total arrecadado e doado e até mostrar as instituições que estão sendo ajudadas, dentre outras formas possíveis de fazer com que o consumidor fique mais consciente em relação à campanha e minimize o seu nível de ceticismo.

Esse resultado também é interessante para o meio acadêmico, pois dá continuidade às pesquisas sobre CRM no Brasil, com foco no comportamento do consumidor. Esse ainda é um tema pouco discutido em revistas de Administração bem conceituadas no ranking Qualis Capes. Sendo assim, a presente pesquisa complementa os estudos existentes e abre as portas para novas pesquisas sobre o tema.

Por outro lado, o estudo possui limitações, já que foi feito considerando somente um produto, a pasta de dente, e um tipo de campanha, a doação para uma instituição que contribui para a alfabetização de crianças carentes. Se for outro produto ou outro tipo de causa, pode ser que esse resultado seja diferente.

Como sugestão para futuras pesquisas, seria interessante investigar outros tópicos abordados na revisão da literatura, como exemplo, a dimensão qualidade do produto. Essa pesquisa também pode ser replicada substituindo o produto pasta de dente por outro, podendo até ser produtos mais caros, que dizem respeito a um maior nível de envolvimento na compra. É importante realizar mais pesquisas sobre o comportamento do consumidor e o CRM no Brasil, para estudar o tema mais profundamente e avançar nas pesquisas sobre esta questão.

\section{Referências Bibliográficas}

ANDREASEN, A. Profits for nonprofits: Find a corporate partner. Harvard Business Review, v. 74, n. 6, p. 47-59, 1996.

BARBoSA, A. O. A Responsabilidade Social Corporativa no Processo de Privatização em Pernambuco: uma leitura institucional. In: ENANPAD, 31., 2007, Rio de Janeiro. Anais... Rio de Janeiro: ANPAD, 2007.

BARNES, N. G.; FITZGIBBONS, D. A. Is Cause Related Marketing in Your Future? Business Forum, v. 16, n. 4, 1991.

BARONE, M. J.; MIYAZAKI, A. D.; TAYLOR, K. A. The Influence of Cause-Related Marketing on Consumer Choice: Does One Good Turn Deserve Another? Journal of the Academy of Marketing Science, v. 28, v. 2, p. 248-262, 2000.

BERGER, I. E.; CUnNinghaM, P. H.; KOZINETS, R. V. Consumer Persuasion Through CauseRelated Advertising. Advances in Consumer Research, v. 26, n. 1, p. 491-497, 1999.

BOULSTRIDGE, E.; CARRIGAN, M. Do consumers really care about corporate responsibility? Highlighting the attitude-behavior gap. Journal of Communication Management, v. 4, n. 4, p. 355-368, 2000.

BRONN, P. S.; VRIONI, A. B. Corporate social responsibility and cause-related marketing: an 
overview. International Journal of Advertising, v. 20, p. 207-222, 2001.

CHEAH, E. T.; CHAN, W. L.; CHIENG, C. L. L. The Corporate Social Responsibility of Pharmaceutical Product Recalls: An Empirical Examination of U.S. and U.K. Markets. Journal of Business Ethics, v. 76, n. 4, p. 427-449, 2007.

COCA-COLA. Disponível em: <http://cocacolabrasil.com.br/>. Acesso em Abril de 2009.

DRUMWRIGHT, M. Socially Responsible Organizational Buying: Environmental Concern as a Noneconomic Buying Criterion. Journal of Marketing, v. 58, n. 3, p. 1-19, 1994.

ELLEN, P. S.; MOHR, L. A.; WEBB, D. J. Charitable Programs and the Retailer: Do They Mix? Journal of Retailing, v. 76, n. 3, p. 393-406, 2000.

FARACHE, F.; PERKS, K. J.; WANDERLEY, L. S. O.; SOUSA FILHO, J. M. Cause Related Marketing: Consumers' Perceptions and Benefits for Profit and Non-Profits Organisations. Brazilian Administration Review, v. 5, n. 3, p. 210-224, 2008.

FILE, K. M.; PRINCE, R. A. Cause Related Marketing and Corporate Philanthropy in the Privately Held Enterprise. Journal of Business Ethics, v. 17, p. 1529-1539, 1998.

FISHER, D. American Philanthropy and the Social Sciences in Britain, 1919-1939; The Reproduction of a Conservative Ideology. Sociological Review, v. 28, n. 2, p. 277-315, 1980.

GRAU, S. L.; FOLSE, J. A. G. Cause-Related Marketing (CRM): The Influence of Donation Proximity and Message-Framing Cues on the Less-Involved Consumer. Journal of Advertising, v. 36, n. 4, p. 19-33, 2007.

HEUGENS, P; DENTCHEV, N. Taming Trojan Horses: Identifying and Mitigating Corporate Social Responsibility Risks. Journal of Business Ethics, v. 75, p. 151-170, 2007.

HOND, F. D.; BAKKER, F. G. A. Ideologically Motivated Activism: How Activist Groups Influence Corporate Social Change Activities. Academy of Management Review, v. 32, n. 3, p. 901-924, 2007.

Instituto para o Desenvolvimento do Investimento Social - IDIS. Disponível em: <http://idis.org.br/iniciativas/marketing-relacionado-a-causas>. Acesso em Abril de 2009.

KLEIN, J. G. Corporate Social Responsibility: A Consumer Perspective. Advances in Consumer Research, v. 31, p. 101-103, 2004.

KOTLER, P.; ANDREASEN, A. Strategic Marketing for Nonprofit Organizations. New Jersey: Prentice Hall, 1996.

KOTLER, P.; ARMSTRONG, G. Princípios de Marketing. Rio de Janeiro: Prentice-Hall do Brasil, 1998.

LARSON, B.V.; FLAHERTY, K. E.; ZABLAH, A. R.; BROWN, T. J.; WIENER, J. L. Linking cause-related marketing to sales force responses and performance in a direct selling context. Journal of the Academy of Marketing Science, v. 36, p. 271-277, 2008.

MACHADO, S. K.; DAMACENA, C. Percepção dos Consumidores Acerca do Marketing Relacionado a Causas: Uma Revisão da Literatura. Base - Revista de Administração e Contabilidade da Unisinos, v. 3, n. 2, p. 93-101, maio/agosto 2006. 
McDonald's. Disponível em: <http://www.mcdonalds.com.br/net2/mcdiafeliz/default.aspx>. Acesso em Abril de 2009.

MEYER, H. When the cause is just. Journal of Business Strategy, v. 20, n. 6, p. 27-31, 1999.

MILLER, C. Tapping into women's issues is potent way to reach market. Marketing News, v. 27, n. 25, p. 1-13, 1993.

MOHR, L. A.; WEBB, D. J. The Effects of Corporate Social Responsibility and Price on Consumer Responses. The Journal of Consumer Affairs, v. 39, n. 1, p. 121-147, 2005.

MOHR, L. A.; WEBB, D. J.; HARRIS, K. E. Do consumers expect companies to be socially responsible? The impact of corporate social responsibility on buying behavior. The Journal of Consumers Affairs, v. 35, n. 1, p. 45-72, 2001.

MULLEN, J. Performance-Based Corporate Philanthropy: How "Giving Smart" Can Further Corporate Goals. Public Relations Quarterly, v. 42, n. 2, p. 42-48, 1997.

NOVAIS, F. C.; SOUSA, C. V.; MELO, J. M. C.; SANTOS, F. L. Marketing Relacionado as Causas como Vantagem Competitiva: um estudo com jovens universitários na cidade de Belo Horizonte. In: SEMEAD - Seminários em Administração, 13., 2010, São Paulo. Anais... São Paulo, 2010.

OSTERHUS, T. L. Pro-Social Consumer Influence Strategies: When And How Do They Work? Journal of Marketing, v. 61, n. 4, p. 16-29, 2007.

PASSADOR, C. S.; CANOPF, L.; PASSADOR, J. L. Apontamentos sobre a Responsabilidade Social no ENANPAD: a construção de um conceito? In: ENANPAD, 29., 2005, Brasília. Anais... Brasília: ANPAD, 2005.

PEREIRA, M. S.; CABRAL, J. E. O. Determinantes de Sucesso na Implementação de Programas de Marketing Relacionado a Causas. REGE - Revista de Gestão USP, v. 18, n. 1, p. 111-127, 2011.

POLONSKY, M. J.; WOOD, G. Can the Overcommercialization of Cause-Related Marketing Harm Society? Journal of Macromarketing, v. 21, n. 1, p. 8-22, 2001.

PORTER, M. E.; KRAMER, M. R. The Competitive Advantage of Corporate Philanthropy. Harvard Business Review, v.80, n. 12, p. 56-68, 2002.

PRACEJUS, J. W.; OLSEN, G. D. The role of brand/cause fit in the effectiveness of cause-related marketing campaigns. Journal of Business Research, v. 57, p. 635-640, 2004.

PTACEK, J. J.; SALAZAR, G. Enlightened self-interest: selling business on the benefits of cause related marketing. NonProfit World, v. 15, n. 4, p. 9-15, 1997.

RANDEL, A. E. The Maintenance of an Organization's Socially Responsible Practice. Business \& Society, v. 41, n. 1, p. 61-83, 2002.

RODRÍGUEZ, L. C.; LEMASTER, J. Voluntary Corporate Social Responsibility Disclosure: SEC “CSR Seal of Approval". Business \& Society, v. 46, n. 3, p. 370-385, 2007.

ROSS, J. K.; PATTERSON, L. T.; STUTTS, M. A. Consumer Perceptions of Organizations That Use Cause-Related Matketing. Journal of the Academy of Marketing Science, v. 20, n. 1, p. 93-97, 1992.

SHELL, A. Cause Related Marketing: Big Risks, Big Potential. Public Relations Journal, v. 45, n. 


\section{$7,1989$.}

SMITH, C. The new corporate philanthropy. Harvard Business Review, v. 72, n. 3, p. 105-116, 1994.

SMITH, S. M.; ALCORN, D. S. Cause Marketing: A New Direction in the Marketing of Corporate Responsibility, Journal of Consumer Marketing, v. 8, n. 3, p. 19-35, 1991.

SMITH, W.; HIGGINS, M. Cause-Related Marketing: Ethics and the Ecstatic. Business \& Society, v. 39, n. 3, p. 304-322, 2000.

STRAHILEVITZ, M.; MYERS, J. G. Donations to Charity as Purchase Incentives: How Well They Work May Depend on What You Are Trying to Sell. Journal of Consumer Research, v. 24, n. 4, p. 434-446, 1998.

TILL, B. D.; NOWAK, L. L. Toward effective use of cause-related marketing alliances. The Journal of Product \& Brand Management, v. 9, n. 7, p. 472-484, 2000.

VARADARAJAN, P. R.; MENON, A. Cause-Related Marketing: A Coalignment of Marketing Strategy and Corporate Philanthropy. Journal of Marketing, v. 52, p. 58-74, 1988.

WEBB, D. J.; MOHR, L. A. A Typology of Consumer Responses to Cause-Related Marketing: From Skeptics to Socially Concerned. Journal of Public Policy \& Marketing, v. 17, n. 2, p. 226-238, 1998.

YOUN, S.; KIM, H. Antecedents of Consumer Attitudes toward Cause-Related Marketing. Journal of Advertising Research, v. 48, n.1, p. 123-137, 2008 